\title{
Time-temperature-transformation (TTT) diagram of a dual-curable off-stoichiometric epoxy-amine system with latent reactivity
}

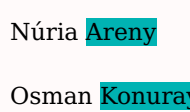

\section{Xavier Fernàndez-Francos}

xavier.fernandez@upc.edu

Josep M.

Josep M. Morancho

Xavier Ramis

Thermodynamics Laboratory, ETSEIB, Universitat Politècnica de Catalunya, Av. Diagonal 647, 08028, Barcelona, Spain

${ }^{*}$ Corresponding author.

\section{Abstract}

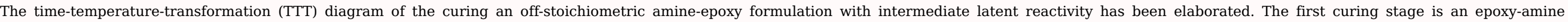

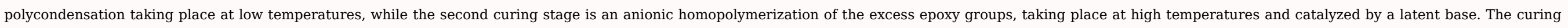

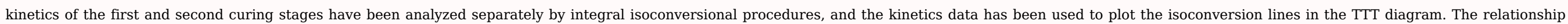

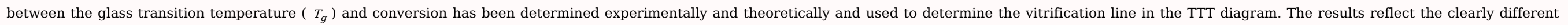

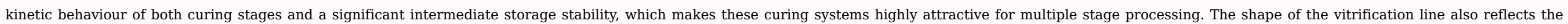

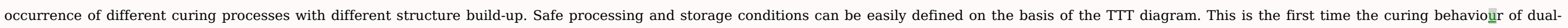
curing formulations is illustrated in such a clear and concise way thanks to the TTT diagram.

Keywords: Epoxy; Diamine; Dual-Curing; Latent base; Thermosets; Time-Temperature-Transformation (TTT) diagram

\section{Introduction}

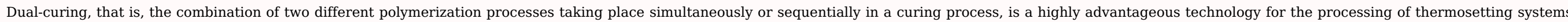

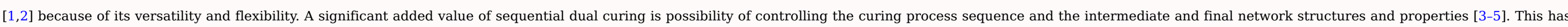

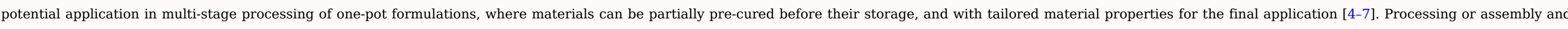

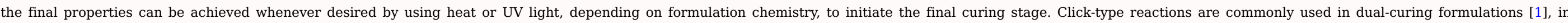

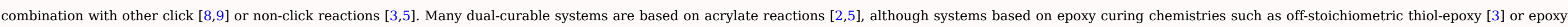
amine $[4,10]$ formulations, or other epoxy systems [11], are also gaining interest in the recent years.

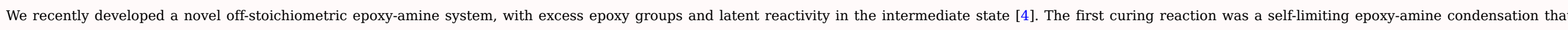

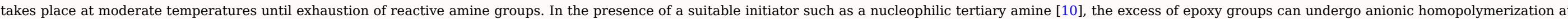

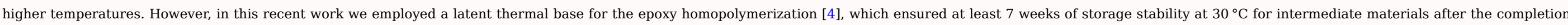

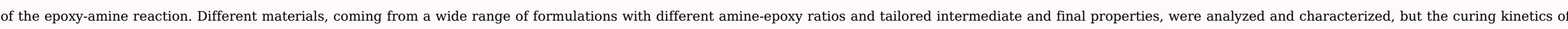




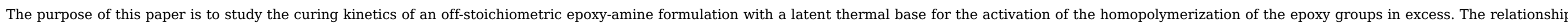

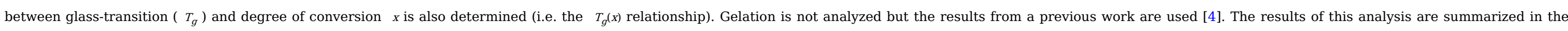

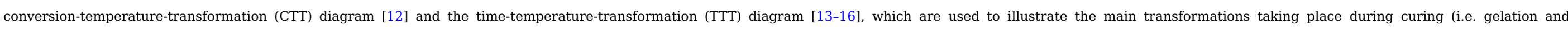

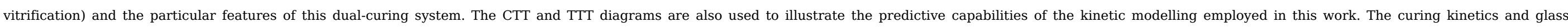

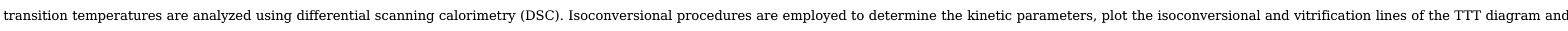
simulate other curing programmes.

\section{Experimental}

\subsection{Materials}

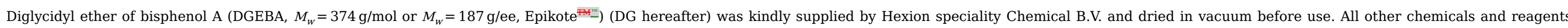

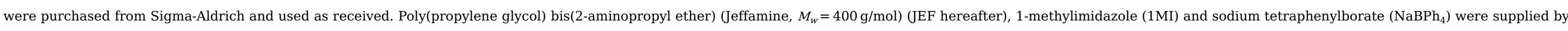

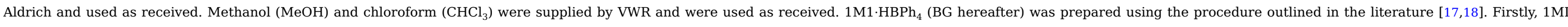

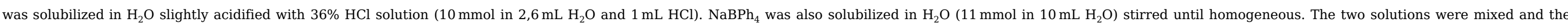

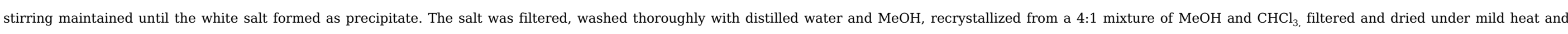

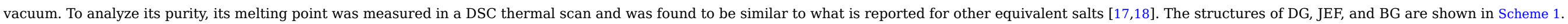

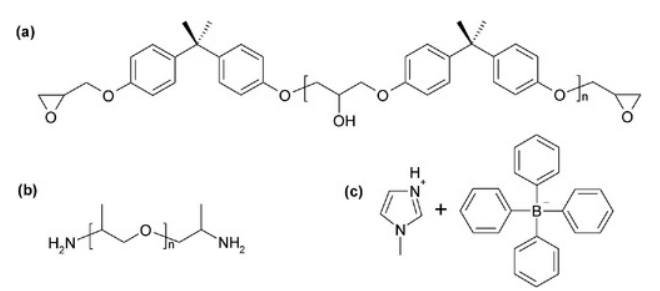

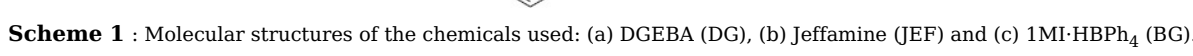

\section{alt-text: Scheme 1}

\subsection{Preparation of the curing mixtures}

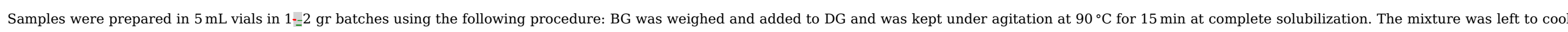

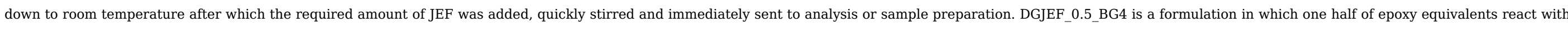

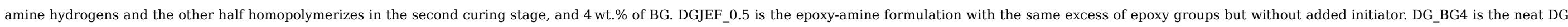
formulation with $4 \mathrm{wt} . \%$ of BG. The details of the composition of the formulations are shown in Table 1.

Table $1 \div$ Notation and composition of the formulations studied in this work.

\begin{tabular}{|c|c|c|c|c|c|}
\hline Formulation & $r^{\mathrm{a}}$ & $D G(w t . \%)$ & $J E F(w t . \%)$ & $B G(w t . \%)$ & $e q_{B G} / e e^{\mathrm{b}}$ \\
\hline DGJEF_0.5 & 0.5 & 78.9 & 21.1 & 0 & 0 \\
\hline DGJEF_0.5_BG4 & 0.5 & 75.7 & 20.3 & 4 & 0.0245 \\
\hline DG_BG4 & 0 & 96 & 0 & 4 & 0.0194 \\
\hline
\end{tabular}




\subsection{Experimental techniques}

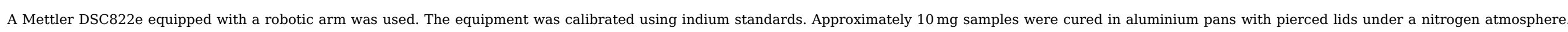

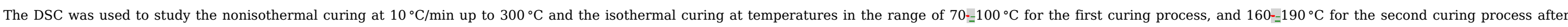
precuring of the samples at $90^{\circ} \mathrm{C}$ for 240 minttes. The degree of cure of the epoxy groups, $x$, and the reaction rate, $d x / d t$, were calculated as follows:

$$
x=\frac{\Delta h_{T}}{\Delta h_{\text {total }}} x=\frac{\Delta h_{t}}{\Delta h_{\text {total }}}
$$

$\frac{d x}{d t}=\frac{d h / d t}{\Delta h_{\text {total }}}$

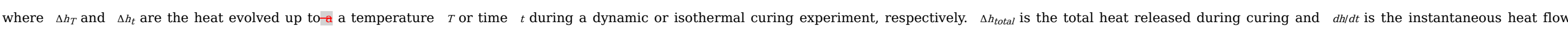
released.

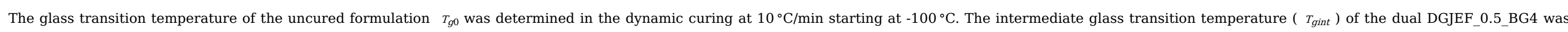

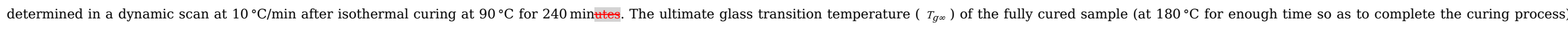

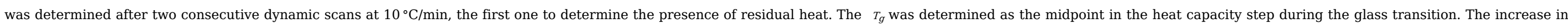
heat capacity during the glass transition, $\Delta C_{p}$, was also determined. The DIN method, included in the STARe software by Mettler, was used for these determinations.

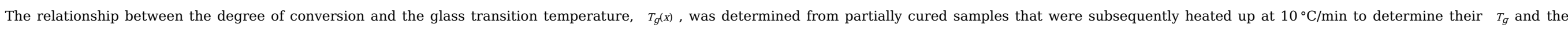
residual heat $\Delta h_{r e s}$, which allowed to determine the degree of conversion as:

$$
x=1-\frac{\Delta h_{\text {res }}}{\Delta h_{\text {total }}}
$$

\section{Theoretical}

\subsection{Curing kinetics}

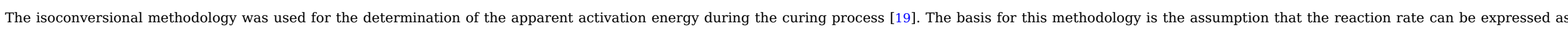
separate functions of conversion $x$ and temperature $T$ as:

\section{$x=1-\frac{\Delta h_{\text {res }}}{\Delta h_{\text {total }}} \frac{d x}{d t}=k(T) \cdot f(x)$ (The whole equation was wrong. Please check the original manuscript. it should be $\mathrm{dx} / \mathrm{dt}=\mathrm{k}(\mathrm{T}) \cdot \mathrm{f}(\mathrm{x})$. I have already corrected it.)}

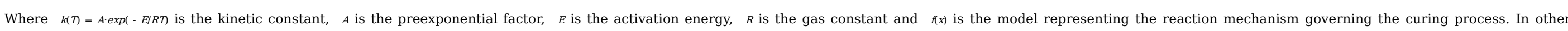

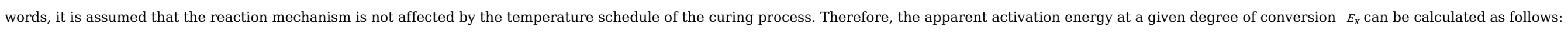
$x=1-\frac{\Delta h_{\text {res }}}{\Delta h_{\text {total }}} \frac{d \ln (d x / d t)}{d T^{-1}}=\frac{d \ln (f(x))}{d T^{-1}}+\frac{d \ln (k(T))}{d T^{-1}} \equiv-\frac{E_{x}}{R} \frac{d \ln (d x / d t)}{d T^{-1}}=\frac{d \ln (f(x))}{d T^{-1}}+\frac{d \ln (k(T))}{d T^{-1}} \equiv-\frac{E_{x}}{R}$ origin $\ln \left(A_{X^{\prime}}(x)\right)$.

Rearrangement and integration of the rate expression leads to: 
Under isothermal conditions, this leads to the following expression, taking natural logarithms:

$$
\ln t=\ln \left(\frac{g(x)}{A}\right)+\frac{E}{R \cdot T}
$$

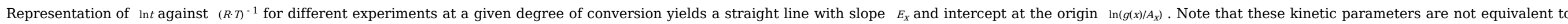

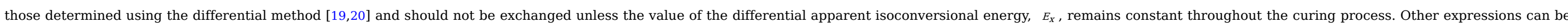

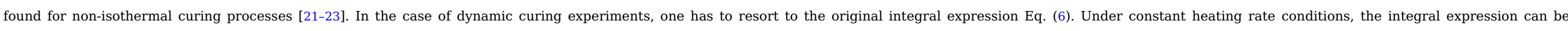
rewritten as:

$$
\frac{g(x)}{A}=\frac{1}{\beta} \cdot \int_{0}^{T} \exp (-E / R \cdot T) \cdot d T=\frac{1}{\beta} \cdot \frac{E}{R} \cdot p(y)
$$

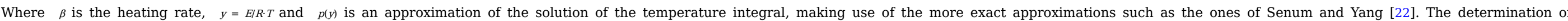

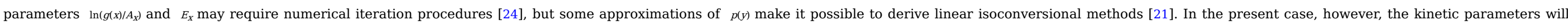
only be determined from isothermal experiments.

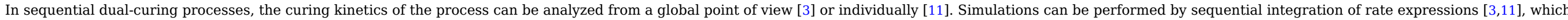

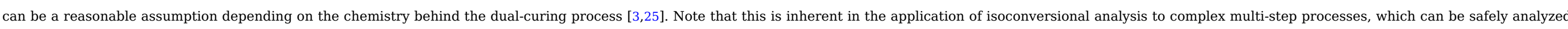
using isoconversional methods providing the coexisting processes are not competitive [26] but sequential [19], as in some dual-curing systems [3].

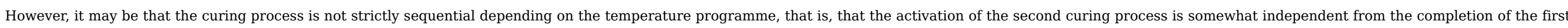

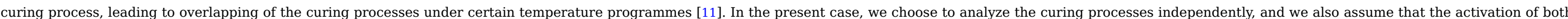

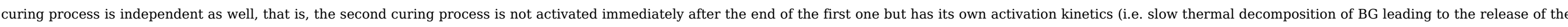

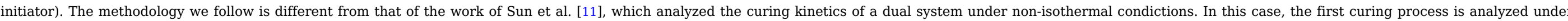

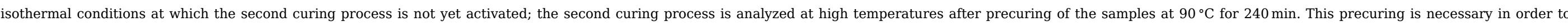
complete the first curing process but avoiding premature activation of the second one.

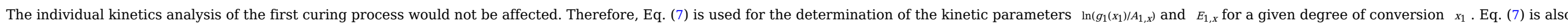
used for the isothermal simulation at other temperatures.

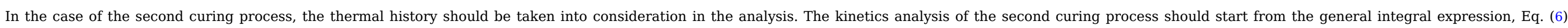
Taking into account the presence of this preliminary thermal programme, one could write for the second curing process:

$g_{2}(x)=A_{2} \cdot \int_{0}^{t_{1}} \exp \left(-E_{2} / R \cdot T_{1}\right) \cdot d t+A_{2} \cdot \int_{t_{1}}^{t_{1}+t_{2}} \exp \left(-E_{2} / R \cdot T_{2}\right) \cdot d t$

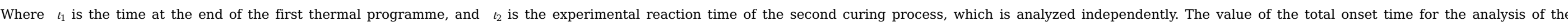

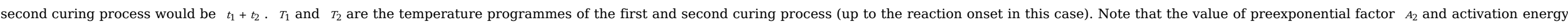
$E_{2}$ should be identical in both integrals, because they correspond to the second curing process

If one calls $I_{1}=\int_{0}^{t_{1}} \exp \left(-E_{2} / R \cdot T_{1}\right) \cdot d t$, and the second curing process is analyzed under isothermal conditions, then:

$\frac{g_{2}(x)}{A_{2}}=I_{1}+\exp \left(-E_{2} / R \cdot T_{2}\right) \cdot t_{2}$ 
Taking natural logarithms:

$\ln t_{2}=\ln \left(\frac{g_{2}(x)}{A_{2}}-I_{1}\right)+\frac{E_{2}}{R \cdot T_{2}}=C+\frac{E_{2}}{R \cdot T_{2}}$

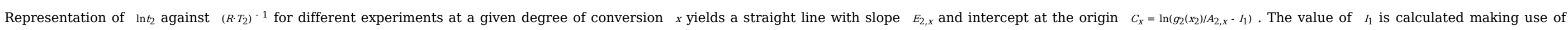

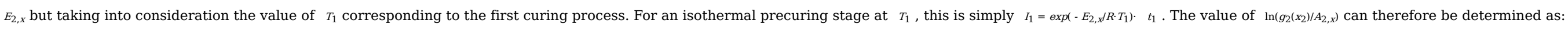

$\ln \left(\frac{g_{2}\left(x_{2}\right)}{A_{2, x}}\right)=\ln \left(e^{C_{x}}+I_{1}\right)$

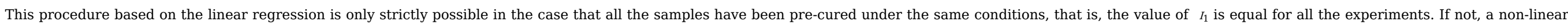
fitting of $\ln \left(g_{2}\left(x_{2}\right) / A_{2, x}\right)$ and $E_{2, x}$ would be necessary

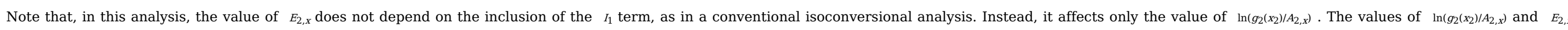
could be used in Eq. (7) to easily predict curing times of the second curing process, assuming the whole process takes place under isothermal conditions, as in the TTT diagram.

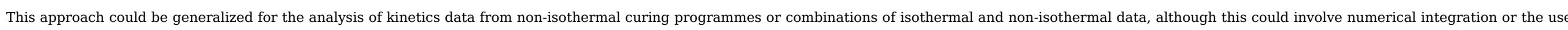
of numerical approximations (i.e. for constant heating rate experiments) and numerical fitting instead of simple linear regression methods.

\section{2 $\mathbf{T}_{\mathrm{g}}-\mathbf{x}$ relationship}

In order to model the dependence of the $T_{g}$ on the degree of conversion $T_{g}(x)$, the expression derived by Venditti and Gillham [27] has been used:

$\ln T_{g}(x)=\frac{(1-x) \cdot \ln T_{g 0}+\lambda \cdot x \cdot \ln T_{g \infty}}{(1-x)+\lambda \cdot x}$

$\lambda=\frac{\Delta C_{p \infty}}{\Delta C_{p 0}}$

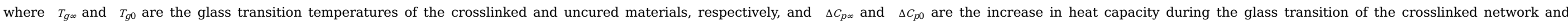

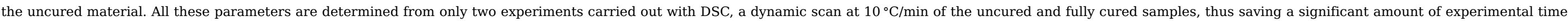

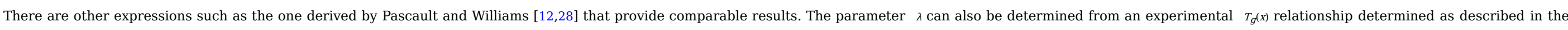
experimental section.

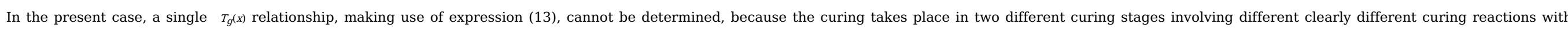

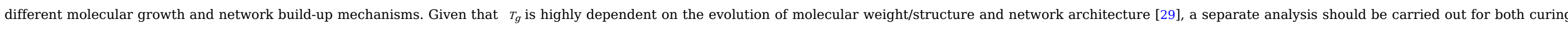

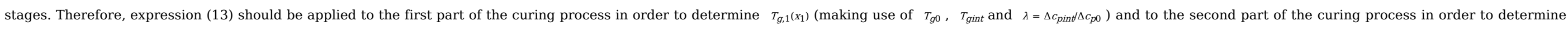

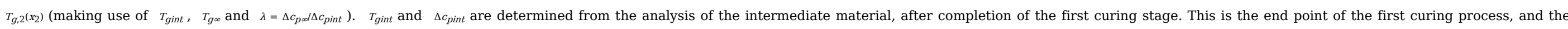
starting point of the second curing process.

\subsection{Time-temperature-transformation (TTT) diagram}

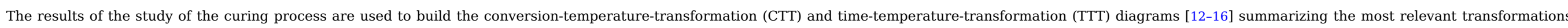

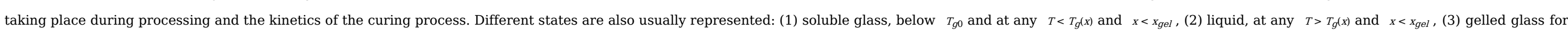

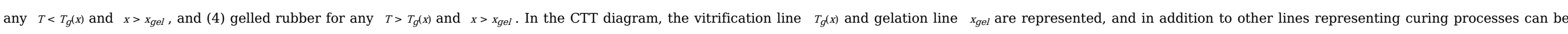

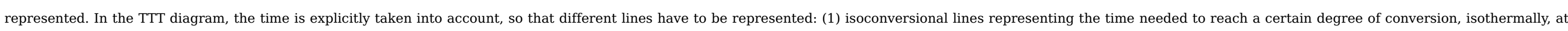




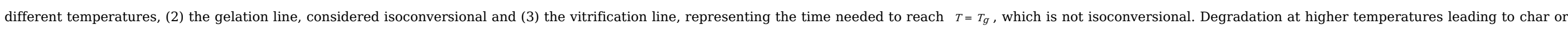

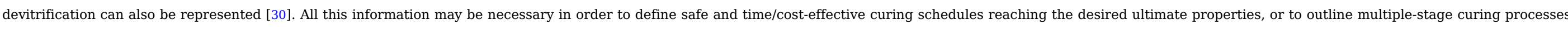
[31].

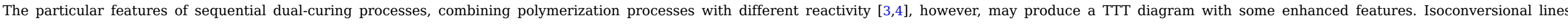
describing the curing kinetics both curing processes should be included, and a vitrification line for each process should be represented as well.

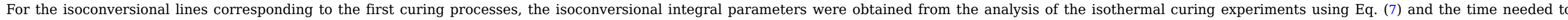
reach a given conversion $x$ was calculated using Eq. (7). Isoconversional lines were represented starting from $T=T_{g, 1}\left(x_{1}\right)$ (the $T_{g}(x)$ relationship of the first curing process) up to $200{ }^{\circ} \mathrm{C}$.

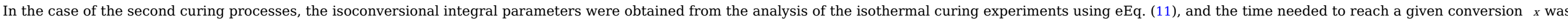
calculated using Eq. (7). Isoconversional lines were represented starting from $T=T_{g, 2}\left(x_{2}\right)$ (the $T_{g}(x)$ relationship of the second curing process) up to $200{ }^{\circ} \mathrm{C}$.

Note that, given the composition of the DGJEF_0.5_BG4 formulation (see Table 1), a global conversion of epoxy groups can be defined as: $x_{\text {epoxy }}=0.5 \cdot x_{1}+0.5 \cdot x_{2}$

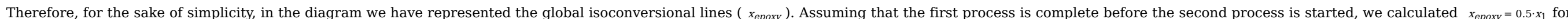
the first curing process, and $x_{e p o x y}=0.5+0.5 \cdot x_{2}$ for the second curing process.

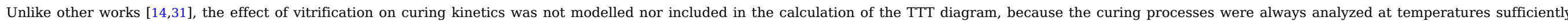
above $T_{g}(x)$. The vitrification lines were finally determined joining the end points of the isoconversional lines.

\subsection{Simulation and prediction of curing schedules}

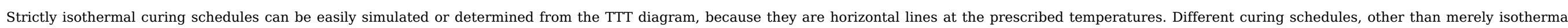

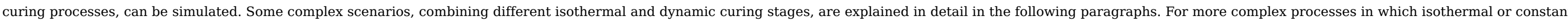

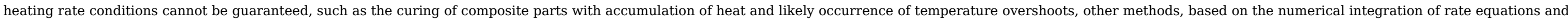
energy balances should be applied [12,32].

\subsubsection{Dynamic curing at constant heating rate}

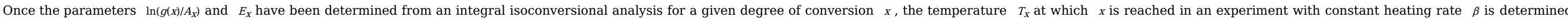

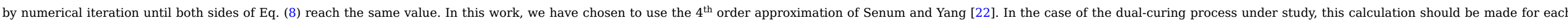

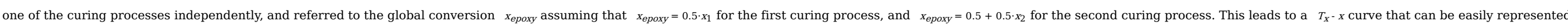

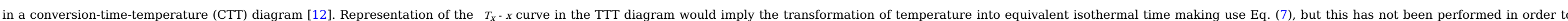
avoid confusions.

\subsubsection{Two consecutive isothermal stages}

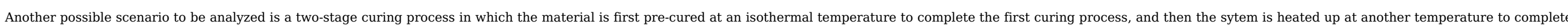

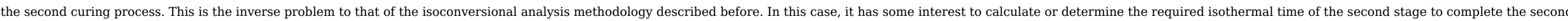

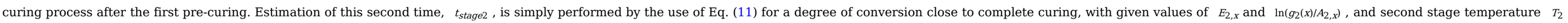

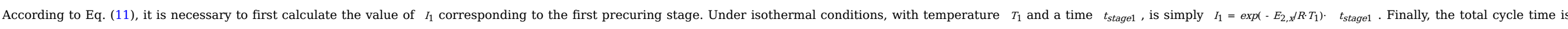
determined as $\quad t_{\text {cycle }}=t_{\text {stage } 1}+t_{\text {stage } 2}$. 


\subsubsection{Two consecutive isothermal stages with heating ramps}

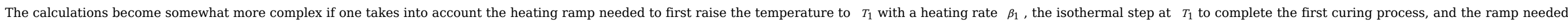
to then raise the temperature to $T_{2}$ with a heating rate $\beta_{2}$.

If one wants to determine, first of all, the time needed in the first isothermal step at $T_{1}, t_{1, \text { isol }}$, to complete the first curing reaction, one can write, starting from Eqs. (6) or (11):

$t_{1, i s o 1}=\left(\frac{g_{1}(x)}{A_{1, x}}-I_{1, d y n 1}\right) \cdot \exp \left(\frac{E_{1, x}}{R \cdot T_{1}}\right)$

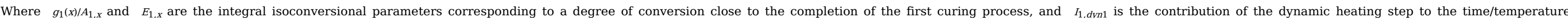
integral (Eq. (6)). $I_{1, d y n 1}$ can be calculated, starting from Eq. (8), as

$I_{1, d y n 1}=\frac{1}{\beta_{1}} \cdot \int_{T_{0}}^{T_{1}} \exp \left(-E_{1, x} / R \cdot T\right) \cdot d T=\frac{1}{\beta_{1}} \cdot \frac{E_{1, x}}{R} \cdot\left[p\left(y_{1, T_{1}}\right)-p\left(y_{1, T_{0}}\right)\right]$

$y_{1, T_{1}}=\frac{E_{1, x}}{R \cdot T_{1}} y_{1, T_{0}}=\frac{E_{1, x}}{R \cdot T_{0}}$

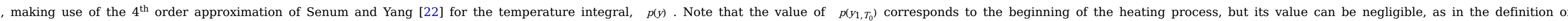
dynamic integral methods. Once this is done, the total time of the first curing stage (heating + isothermal at $T_{1}$ is calculated as:

$t_{\text {stage } 1}=\frac{T_{1}-T_{0}}{\beta_{1}}+t_{1, i s o 1}$

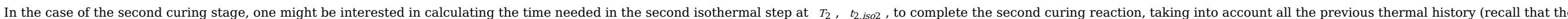
kinetics of second curing stage are modelled as an event independent from the first curing stage):

$t_{2, i s o 2}=\left(\frac{g_{2}(x)}{A_{2, x}}-I_{2, d y n 1}-I_{2, i s o 1}-I_{2, d y n 2}\right) \cdot \exp \left(\frac{E_{2, x}}{R \cdot T_{2}}\right)$

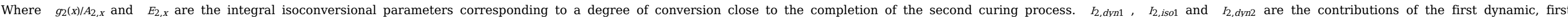
isothermal and second dynamic steps, respectively, to the time/temperature integral (Eq. (6)). They can be calculated using the following set of expressions:

$I_{2, d y n 1}=\frac{1}{\beta_{1}} \cdot \int_{T_{0}}^{T_{1}} \exp \left(-E_{2, x} / R \cdot T\right) \cdot d T=\frac{1}{\beta_{1}} \cdot \frac{E_{2, x}}{R} \cdot\left[p\left(y_{2, T_{1}}\right)-p\left(y_{2, T_{0}}\right)\right]$

$y_{2, T_{1}}=\frac{E_{2, s}}{R \cdot T_{1}} y_{2 \text { Sdiseq, }} T_{0}=\frac{\mathbb{E}_{2, s}}{R \cdot T_{0}}$

$I_{2, i s o 1}=\exp \left(-E_{2, x} / R \cdot T_{1}\right) \cdot t_{1, i s o 1}$

$I_{2, d y n 2}=\frac{1}{\beta_{2}} \cdot \int_{T_{1}}^{T_{2}} \exp \left(-E_{2, x} / R \cdot T\right) \cdot d T=\frac{1}{\beta_{2}} \cdot \frac{E_{2, x}}{R} \cdot\left[p\left(y_{2, T_{2}}\right)-p\left(y_{2, T_{1}}\right)\right]$

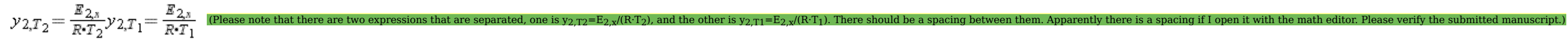

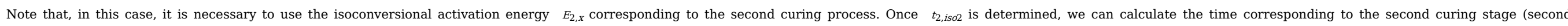
heating + second isothermal) as:

$t_{\text {stage } 2}=\frac{T_{2}-T_{1}}{\beta_{2}}+t_{2, i s o 2}$ 


\section{Results and discussion}

\subsection{Preliminary analysis}

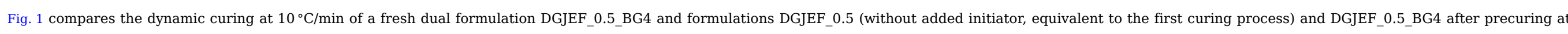

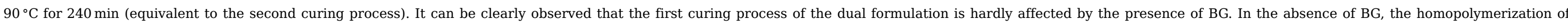

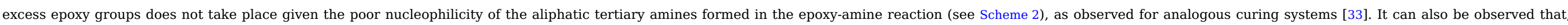

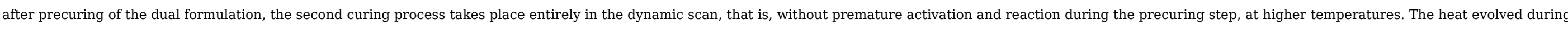

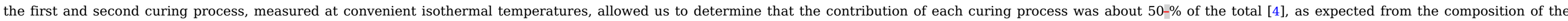

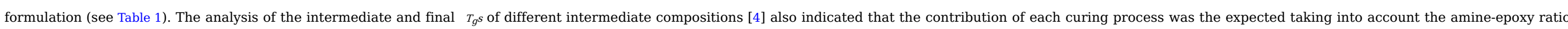
and the excess of epoxy groups.

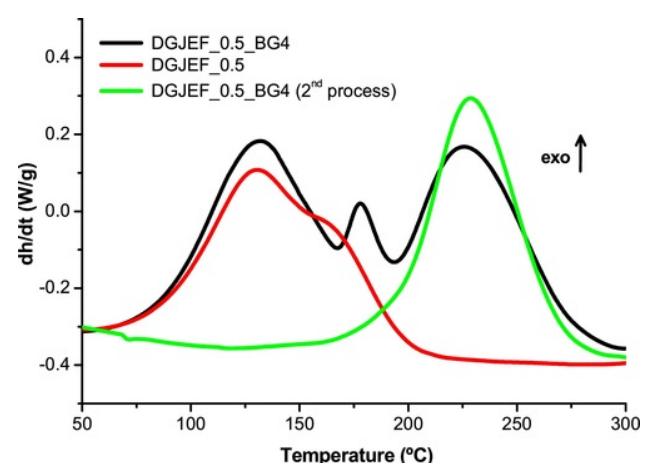

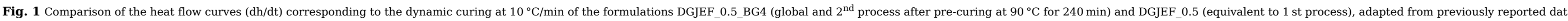
[4].

\section{alt-text: Fig. 1}

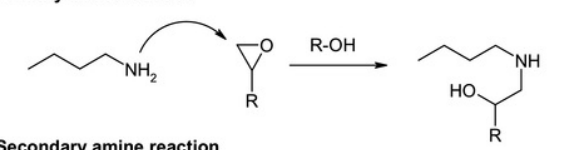

b. Secondary amine reaction

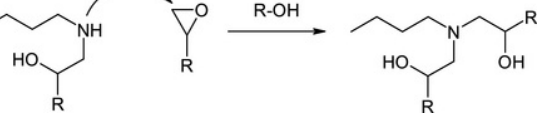

Scheme 2 : Epoxy-amine reaction.

alt-text: Scheme 2

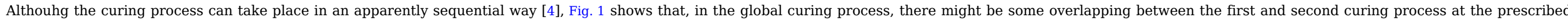

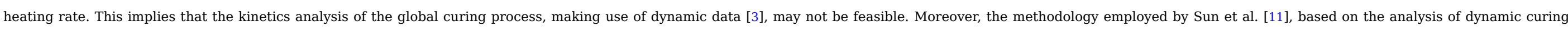
experiments corresponding to each reaction step, may not be feasible either.

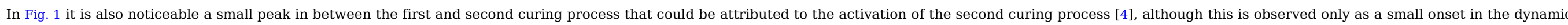




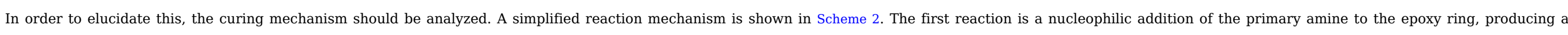

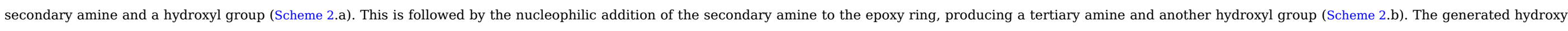

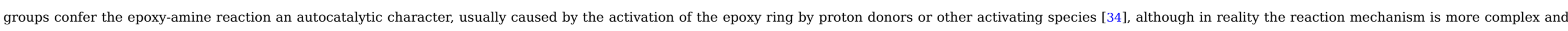
involves the formation a number of reactive and non-reactive complexes [34-37].

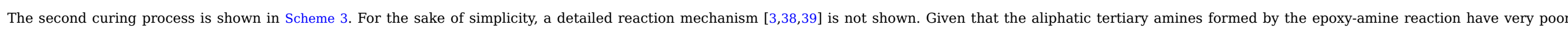

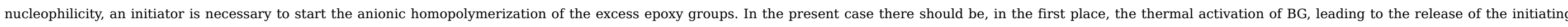

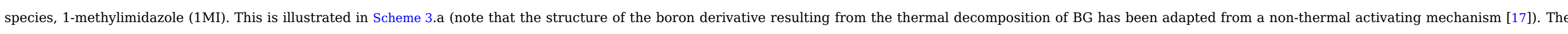

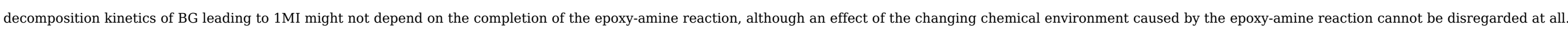

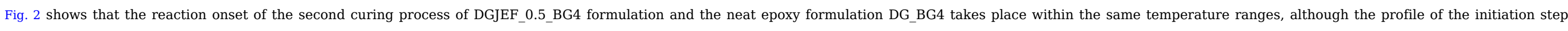

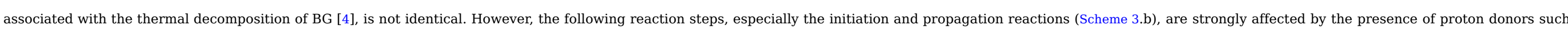

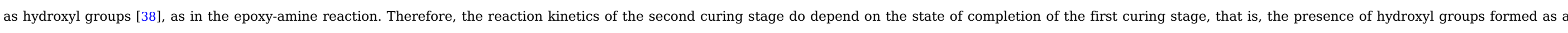

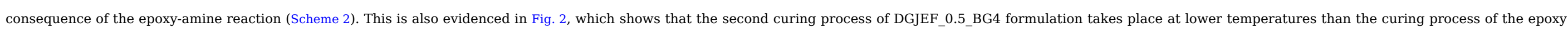
formulation DG_BG4.
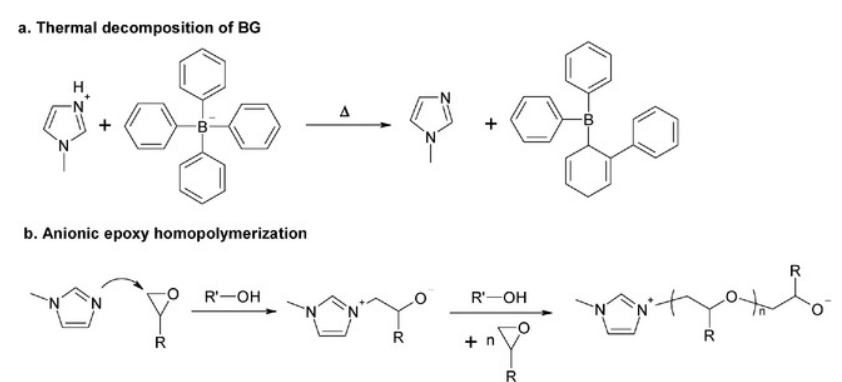

Scheme 3 : Thermal decomposition of BG (a) and anionic epoxy homopolymerization (b).The structure after the thermal decomposition of the initiator has been adapted from a non-thermal activating mechanism [17]. alt-text: Scheme 3

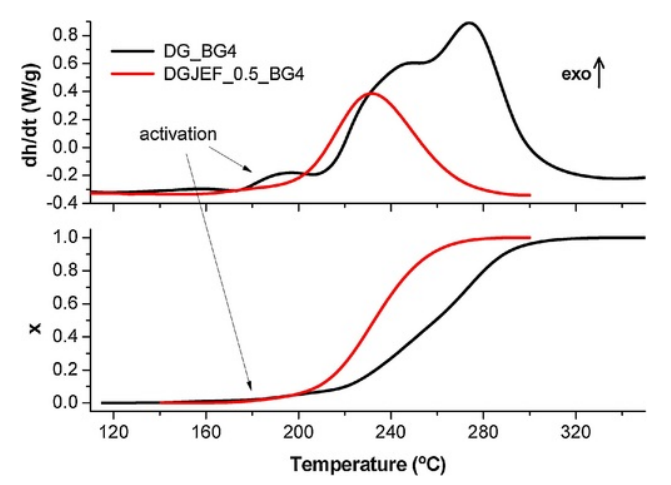

Fig. 2 Comparison of the heat flow (dh/dt) and conversion (x) curves corresponding to the dynamic curing at $10^{\circ} \mathrm{C} / \mathrm{min}$ of the formulations DG_BG4 and DGJEF_0.5_BG4 (2 $2^{\text {nd }}$ process after pre-curing at $900^{\circ} \mathrm{C}$ for 240 min). alt-text: Fig. 2 


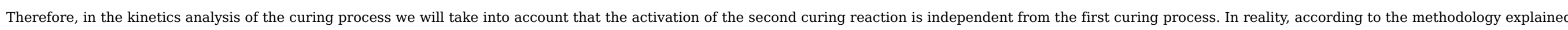

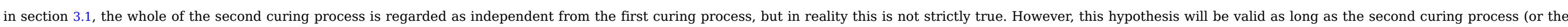
majority of it) takes place once the first curing process is over.

\subsection{Kinetics analysis}

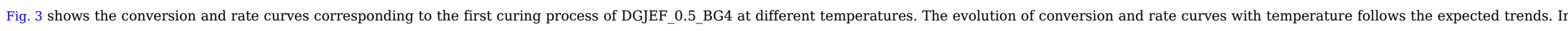

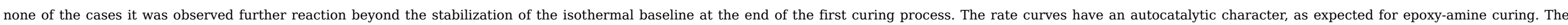
reaction heat measured agreed well with the reaction heat reported previously [4].
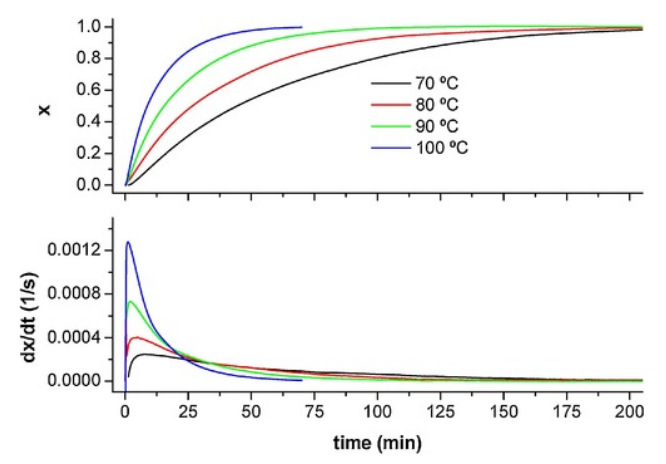

Fig. 3 Conversion $x$ and rate $d x / d t$ for the $1^{\text {st }}$ curing process of DGJEF_0.5_BG4 at different temperatures.

\section{alt-text: Fig. 3}

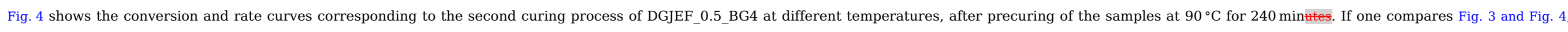

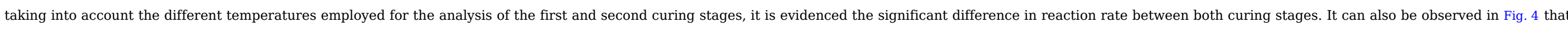

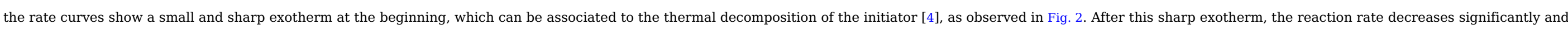

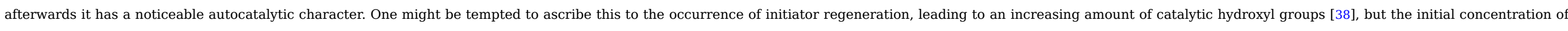

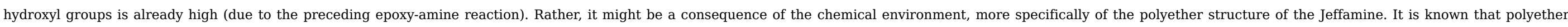

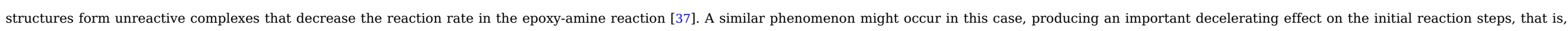
those involving the nucleophilic addition of $1 \mathrm{MI}$ to the epoxy ring. It might also be an influence of the presence of fragments of boron derivatives.

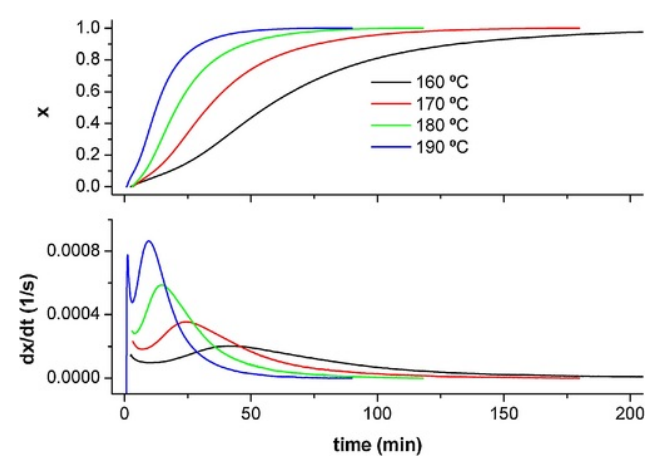

Fig. 4 Conversion $x$ and rate $d x / d t$ for the $2^{\text {nd }}$ curing process at different temperatures, after pre-curing at $90^{\circ} \mathrm{C}$ for $240 \mathrm{~min}$. 


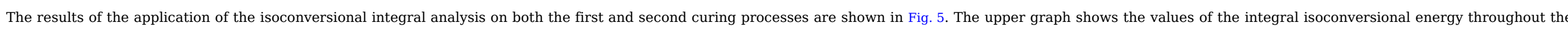

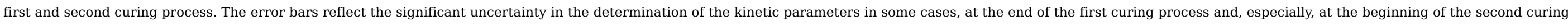

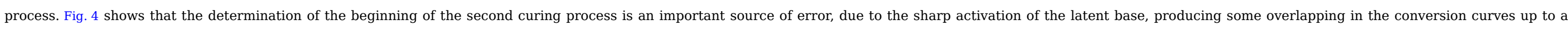
degree of conversion of 0.05-0.10.

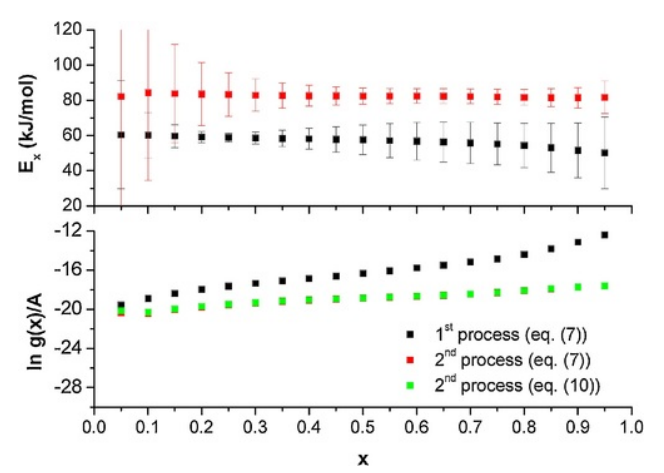

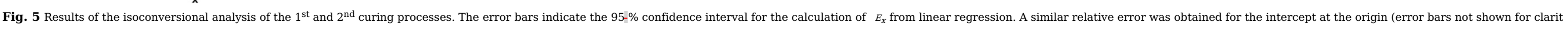
purposes).

\section{alt-text: Fig. 5}

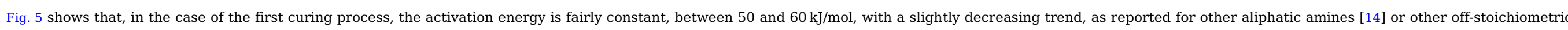

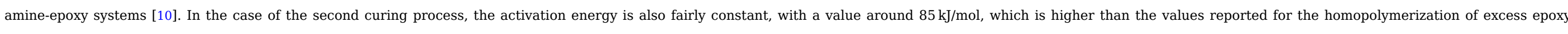

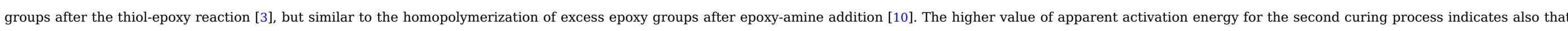

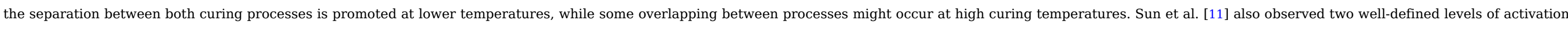
energy for the different stages of the curing process.

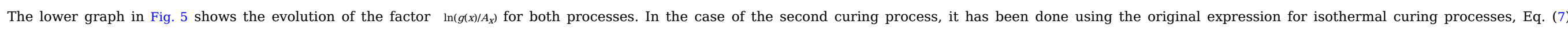

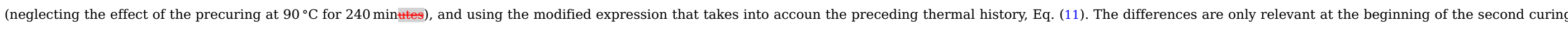

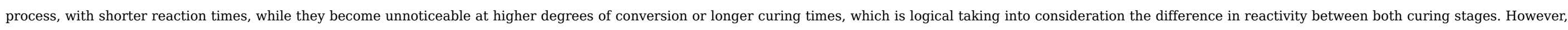
for the sake of consistence, the isoconversional lines of the TTT diagram associated to the second curing process will be calculated using the data determined obtained by means of Eq. (11).

\subsection{Tg-x relationship}

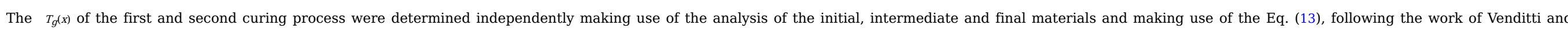

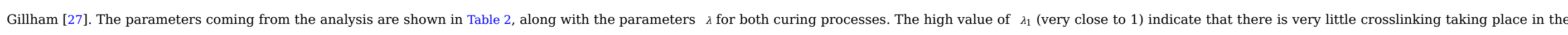

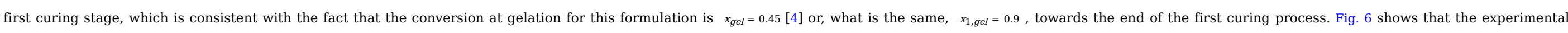

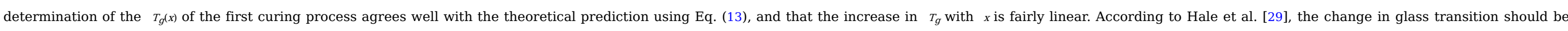

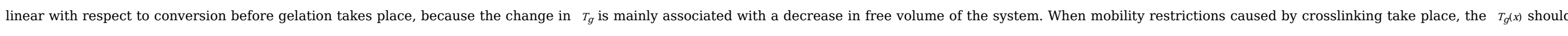

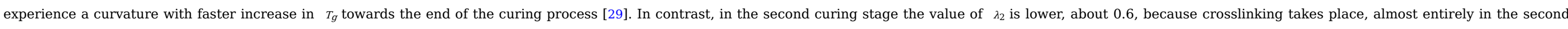
curing stage, in fact.

Table 2 Parameters for the determination of the $T_{g}(x)$ relationship of DGJEF_0.5_BG4 formulation using theoretical expression Eq. (13). 

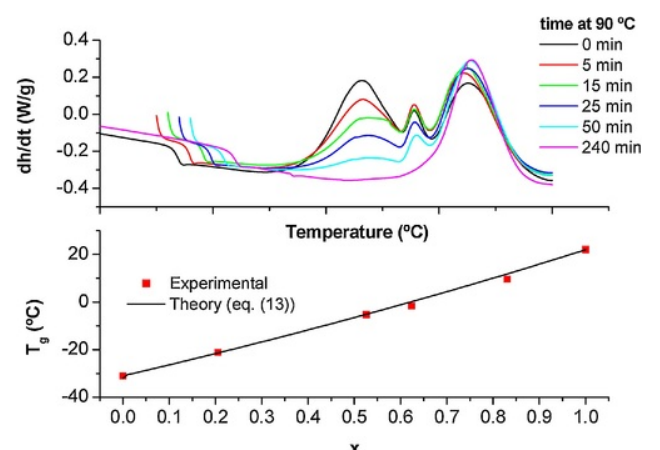

Fig. 6 Experimental determination of the $T_{g}(x)$ relationship for the $1^{\text {st }}$ curing process of DGJEF_0.5_BG4 formulation and comparison with theoretical predictions (Eq. (13))!

\section{alt-text: Fig. 6}

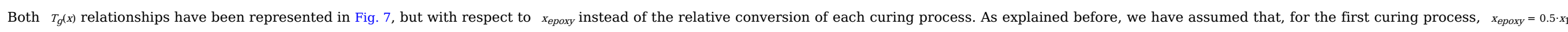

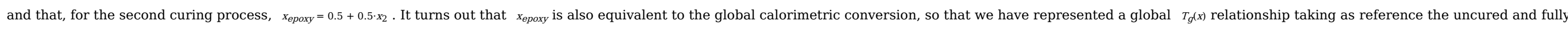

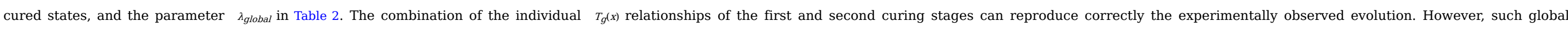

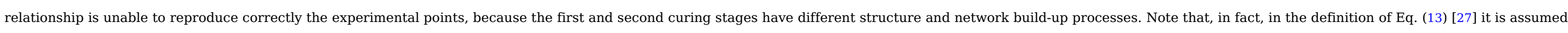

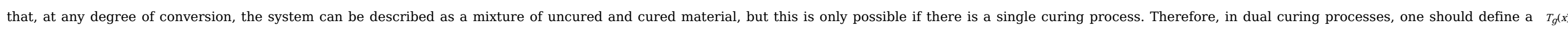

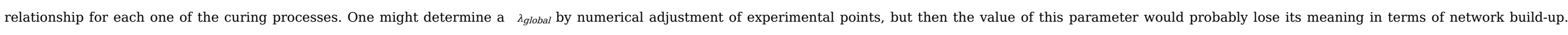
Therefore, we choose to use the combination of the individual relationships in order to properly describe vitrification.

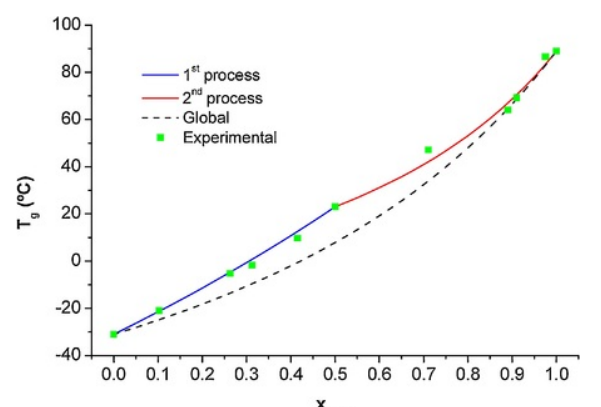




\section{alt-text: Fig. 7}

\subsection{Time-temperature-transformation (TTT) diagram}

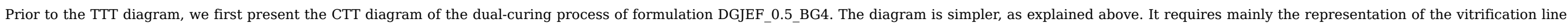

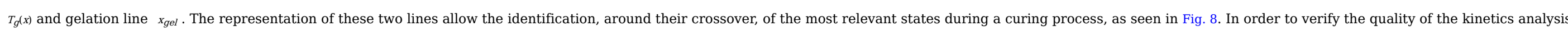

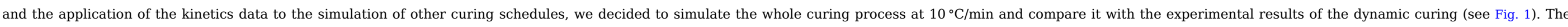

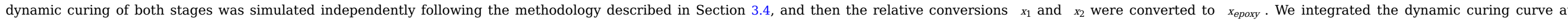

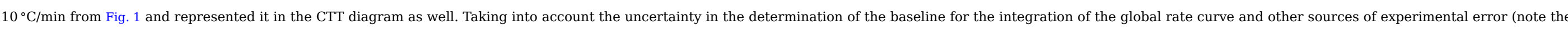

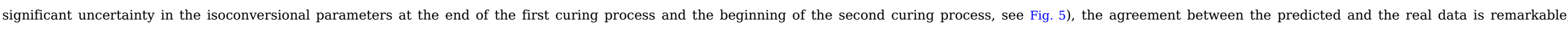

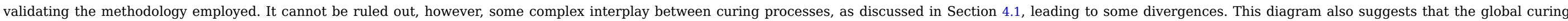
might have been studied using dynamic data, virtually unaffected by vitrification, but the apparently poor separation between curing stages (see Fig. 1) prompted us to use a different methodology.

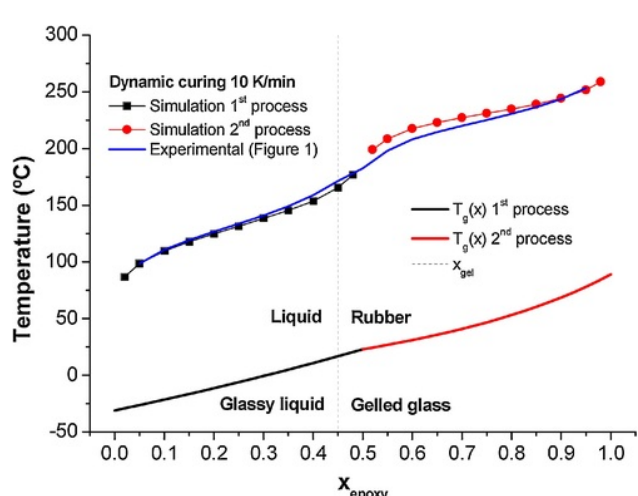

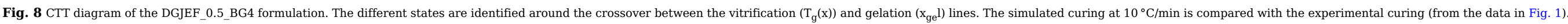
alt-text: Fig. 8

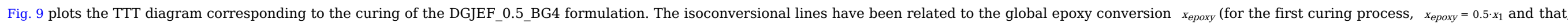

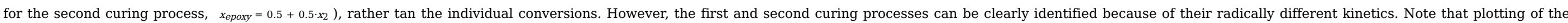

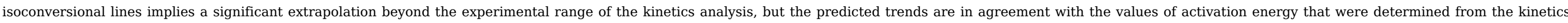

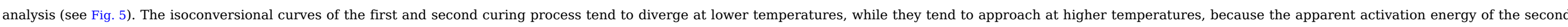
curing process is higher tan that of the first one. The isoconversional line at gelation was determined according to the gel point determined experimentally and reported in our previous work [4] 


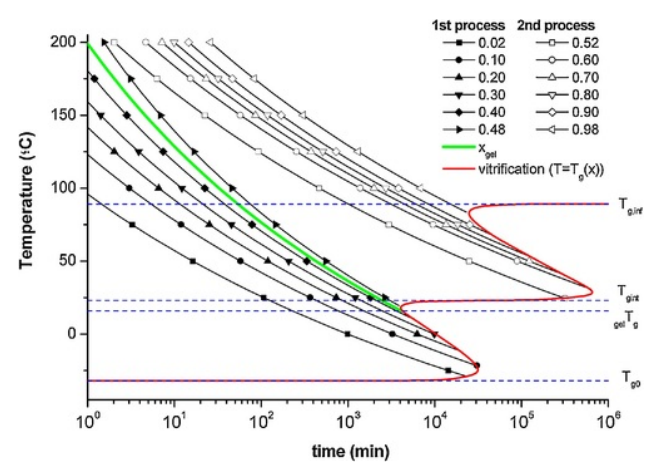

Fig. 9 TTT diagram of the DGJEF_0.5_BG4 formulation. Isoconversional lines are related to $x_{\text {epoxy }}$.

\section{alt-text: Fig. 9}

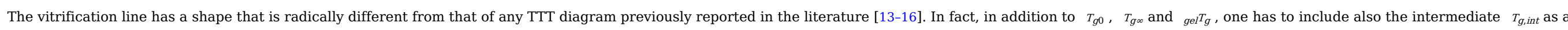

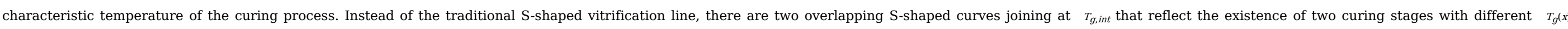

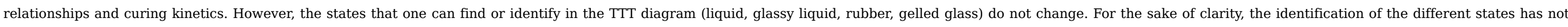
been included in Fig. 9. The isoconversional lines of the first and second curing processes logically end in the vitrification line corresponding to the respective $T_{g}(x)$ relationship.

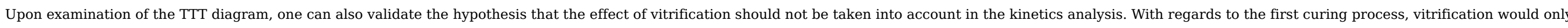

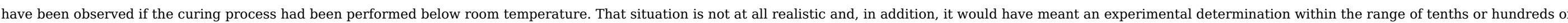

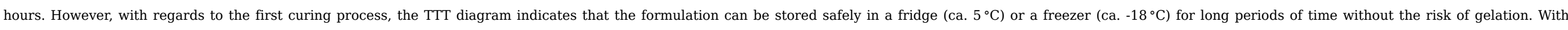
respect to vitrification in the second curing state, the same considerations can be made, but with even longer time scales because of the slower reaction kinetics.

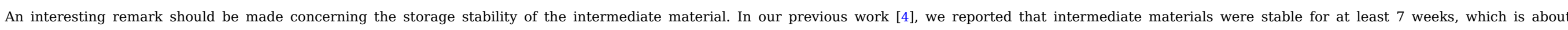

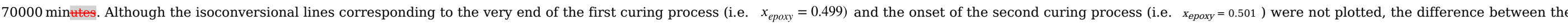

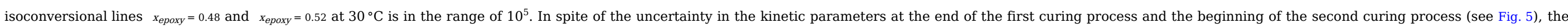
estimation of the isothermal stability at $30^{\circ} \mathrm{C}$ is not that far from our experimental stability measurements [4].

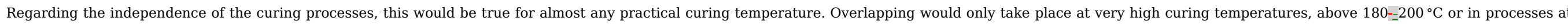

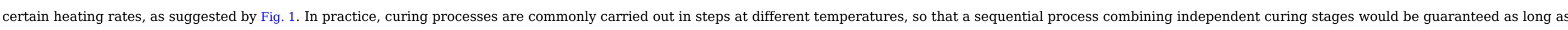

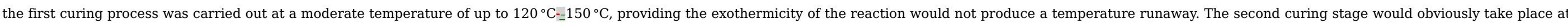
higher temperatures in order to ensure complete cure in a reasonable time.

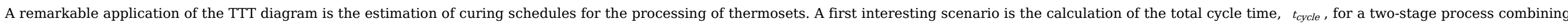

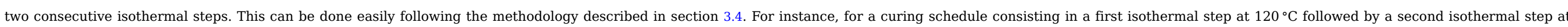

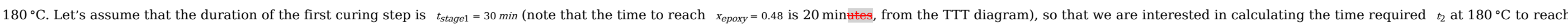

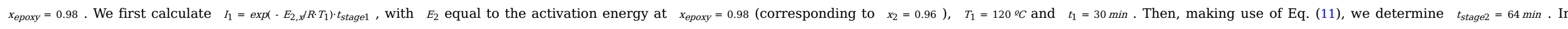

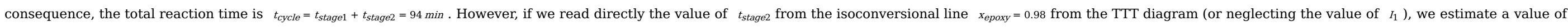

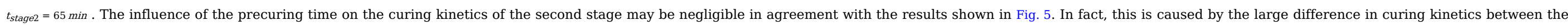
first and second curing stages. 


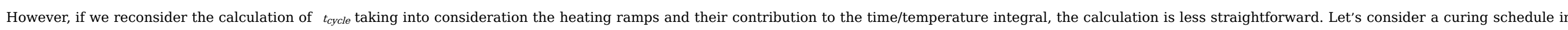

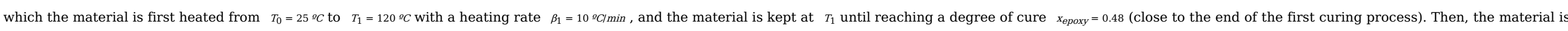

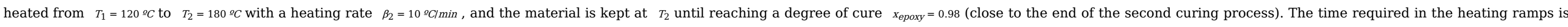

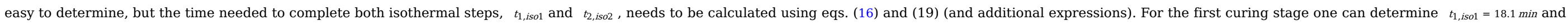

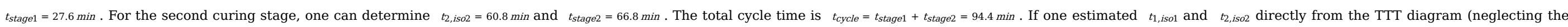

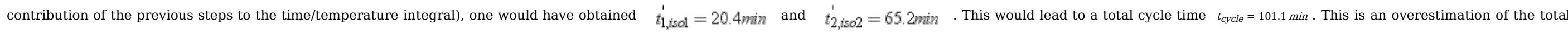

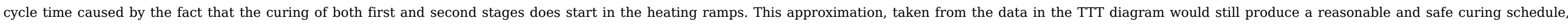

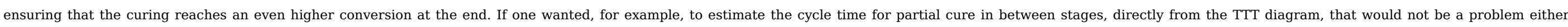

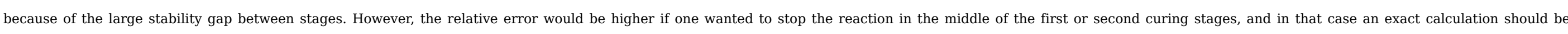
performed instead.

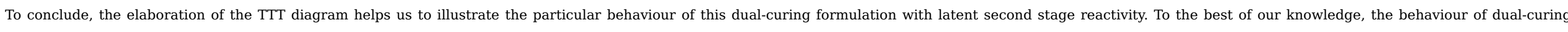

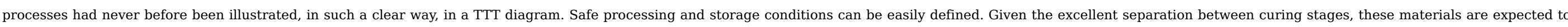

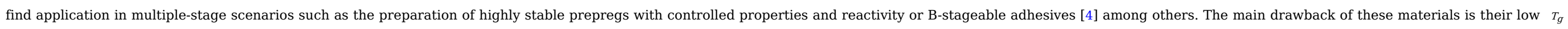

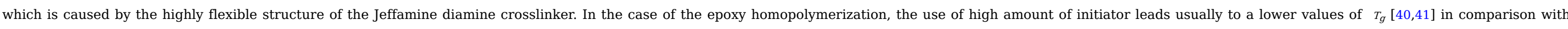

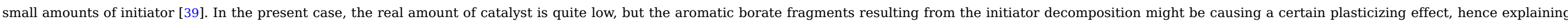

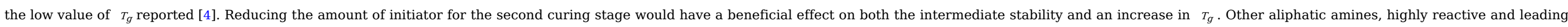
to more rigid network structures, could be used [14,33].

\section{Conclusions}

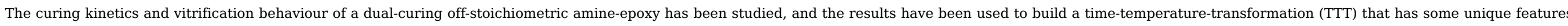
in comparison with conventional curing systems, because of the particular characteristics of this dual-curing system.

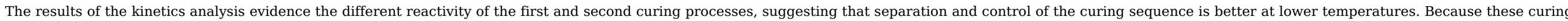
processes have different molecular and structure build-up characteristics, vitrification during curing needs to be defined by two different glass transition-conversion relationships.

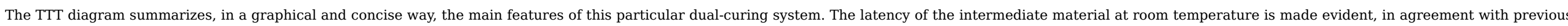

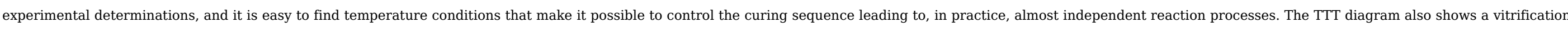

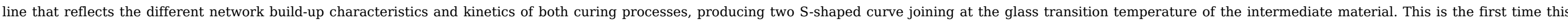
particular behaviour is so clearly shown and illustrated thanks to the TTT diagram.

\section{Acknowledgements}

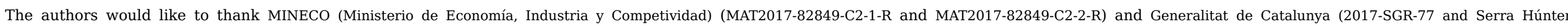
programme) for the financial support.

\section{References}

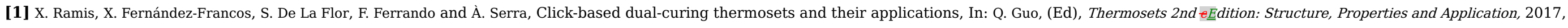
Elsevier.

[2] O. Konuray, X. Fernández-Francos, X. Ramis and À. Serra, State of the art in dual-curing acrylate systems, Polymers $\underline{10}, \underline{2018}$ 


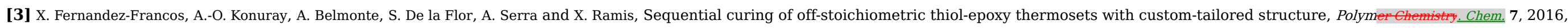
2280-2290.

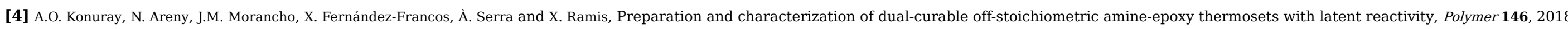
$42-52$.

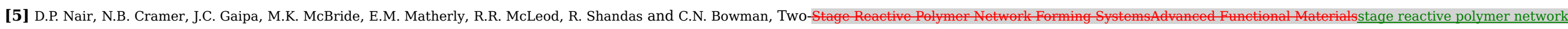

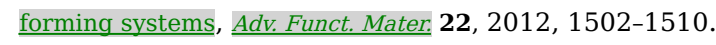

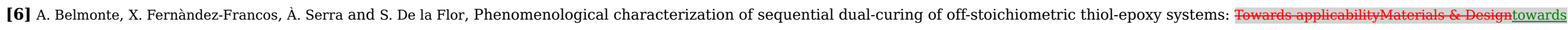
applicability, Mater. \& Des. 113, 2017, 116-127.

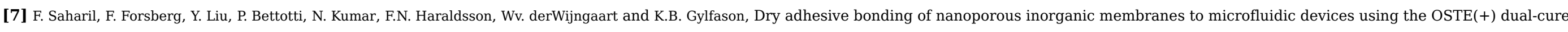
polymer, Joumal of Miemechanies and Mierenginering. Micromech. Microeng. 23, 2013, 025021.

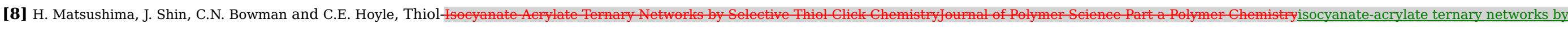
selective thiol-click chemistry, I. Polym. Sci. A Polym. Chem. 48, 2010, 3255-3264.

[9] J.A. Carioscia, J.W. Stansbury and C.N. Bowman, Evaluation and control of thiol-ene/thiol-epoxy hybrid networks, Polymer 48, 2007, $1526-1532$.

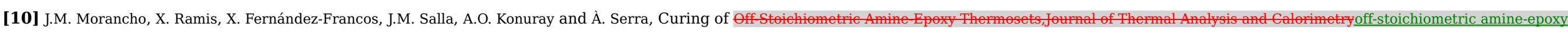
thermosets, I. Therm. Anal. Calorim. 2018, https://doi.org/10.1007/s10973-018-7158-2.

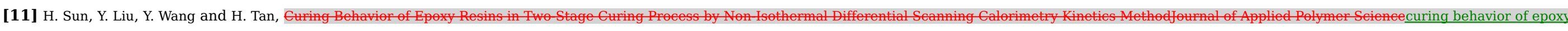
resins in Two-stage curing process by non-isothermal differential scanning calorimetry kinetics method, J. Appl. Polvm. Sci. 131, 2014.

[12] J.P. Pascault, H. Sautereau, J. Verdu and R.J.J. Williams, Thermosetting ĐPolymers, 2002, Marcel Dekker; New York, [etc.].

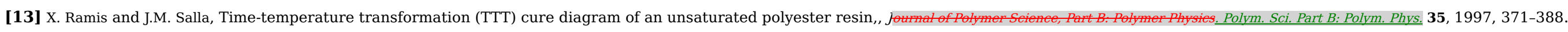

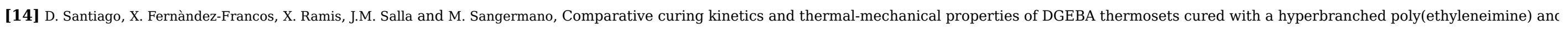
an aliphatic triamine, Thermochimiea. Acta 526, 2011, 9-21.

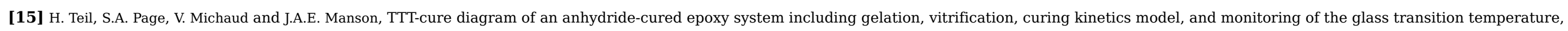
Joumal of Applied Polymer Science. Appl. Polvm. Sci. 93, 2004, 1774-1787.

[16] M.T. Aronhime and J.K. Gillham, Time-Temperature-Transformation (TTT) Cure Diagram of Thermosetting Polymeric Systems, 1986, Springer-Verlag; Berlin, West Ger, 83-113.

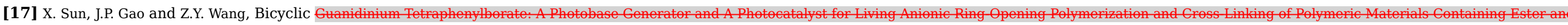

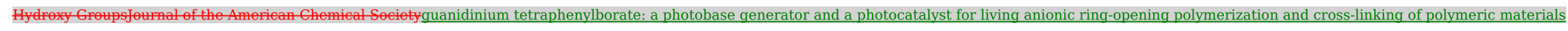
containing ester and hydroxy groups, I. Am. Chem. Soc. 130, 2008, 8130-8131.

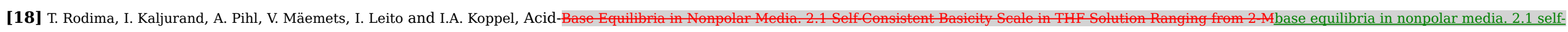
consistent basicity scale in THF solution ranging from 2-methoxypyridine to EtP1(pyrr) PhosphazeneThe Journal of Organic Chemistryphosphazene, I. Org. Chem. 67, 2002 , $1873-1881$.

[19] S. Vyazovkin and N. Sbirrazzuoli, Isoconversional kinetic analysis of thermally stimulated processes in polymers, Macromolecular Rapid Communications. Rapid Commun. 27, 2006, 1515-1532.

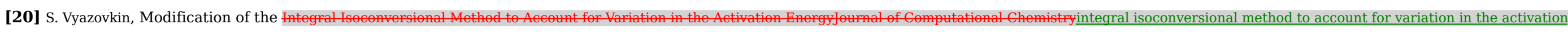


energy, L. Comput. Chem. 22, 2001, 178-183.

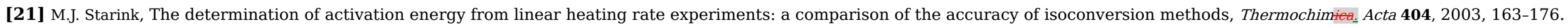

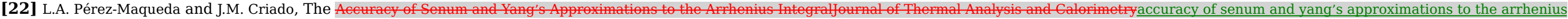
integral, I. Therm. Anal. Calorim. 60, 2000, 909-915.

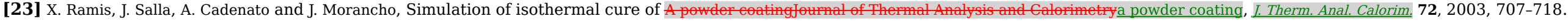

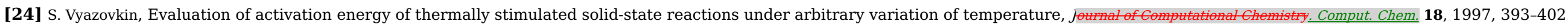

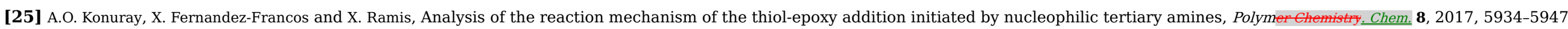

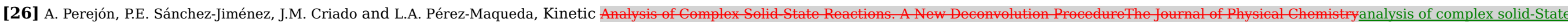
reactions. A New deconvolution procedure, I. Phys. Chem. B 115, 2011, 1780-1791.

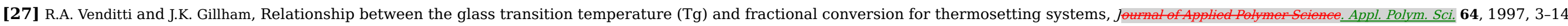

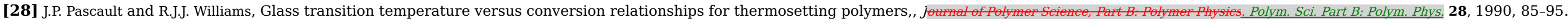

[29] A. Hale, C.W. Macosko and H.E. Bair, Glass transition temperature as a function of conversion in thermosetting polymers, Macromolecules 24, 1991, $2610-2621$.

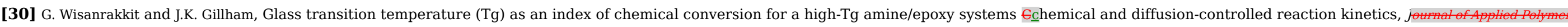
Seienet. Appl. Polym. Sci. 41, 1990, 2885-2929.

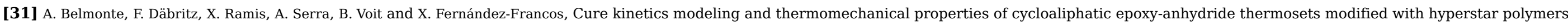
foumal of Polymer Seience Part B. Polymer Physies. Polym. Sci. B Polym. Phys. 52, 2014, 1227-1242.

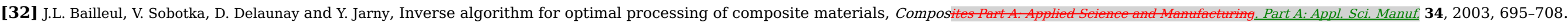

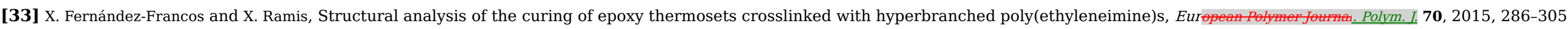

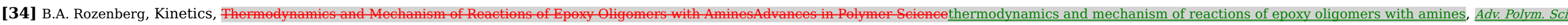
75, 1986, 113-165

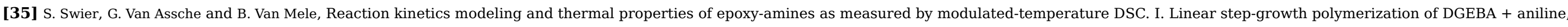
Journal of Applied Polymer Science. Appl. Polym. Sci. 91, 2004, 2798-2813.

[36] H.J. Flammersheim, Kinetics and mechanism of the epoxide-amine polyaddition, Thermochimiea. Acta 310, 1998, 153-159.

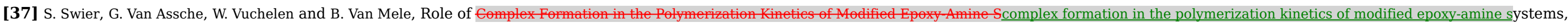
Macromolecules 38, 2005, 2281-2288.

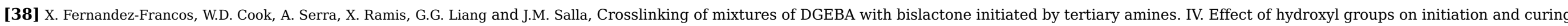
kinetics, Polymer 51, 2010, 26-34.

[39] S.K. Ooi, W.D. Cook, G.P. Simon and C.H. Such, DSC studies of the curing mechanisms and kinetics of DGEBA using imidazole curing agents, Polymer 41, 2000, 3639-3649.

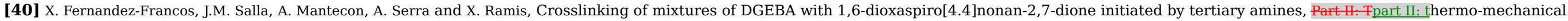
properties and reworkability, Polymer Degradation and Stability. Degrad. Stab. 93, 2008, 760-769. 
[41] I.E. Dell'Erba and R.J.J. Williams, Homopolymerization of epoxy monomers initiated by 4-(dimethylamino)pyridine, Polymer Engine and Seiene. Enq. Sci. 46, 2006, 351-359.

4

Highlights

- Kinetics of a dual-curing system has been studied using isoconversional methods:

- Time-temperature-transformation (TTT) diagram has been elaborated and discussed_

- Unique features of dual-curing systems (kinetics/network build-up) are highlighted_

- Safe multiple-stage curing schedules and storage/stability conditions are predicted,

\section{Queries and Answers}

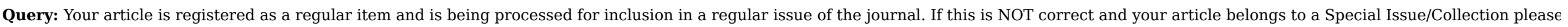
contact d.kaliyaperumal@elsevier.com immediately prior to returning your corrections.

Answer: This is correct.

Query: The author names have been tagged as given names and surnames (surnames are highlighted in teal color). Please confirm if they have been identified correctly.

Answer: Yes

Query: Please check the hierarchy of the section headings and correct if necessary.

Answer: Correct

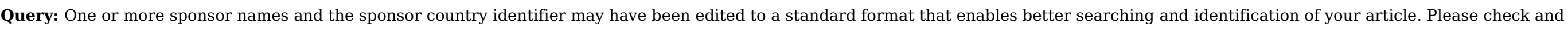
correct if necessary.

Answer: Correct

Query: Please provide page rage or volume/issue for Ref. [10].

Answer: Vol 133 (issue 1) pp 519-527 